\section{Commentary: Modern problems require modern solutions: Fixing the failed WATCHMAN}

\author{
Marc Gillinov, MD, Aaron J. Weiss, MD, and \\ Edward G. Soltesz, MD, MPH
}

The development of less-invasive, nonsurgical alternatives to treat cardiovascular disease has long been a focus of cardiologists and a desire of patients. Efforts along these lines have created a variety of competing procedures, including coronary artery bypass grafting/percutaneous coronary intervention, surgical aortic valve replacement/transcatheter aortic valve replacement, and maze/catheter ablation. In each case, the advent of a percutaneous approach has created the need for surgeons to develop new strategies to employ when the percutaneous interventions fail. Dissemination of surgeons' experience managing complications and failures associated with percutaneous therapies is a much-needed service to our patients and to our specialty. With their insightful report of surgical strategies for a failed WATCHMAN device (Boston Scientific, Plymouth, Minn), Palmer and colleagues ${ }^{1}$ add to our knowledge and inform our management of the left atrial appendage.

The WATCHMAN is a percutaneously deployed device that occludes the left atrial appendage (LAA) and thereby obviates the need for anticoagulation in selected patients with atrial fibrillation (AF). ${ }^{2}$ The device is contraindicated in patients with LAA anatomy not amenable to device

From the Department of Thoracic and Cardiovascular Surgery, Cleveland Clinic, Cleveland, Ohio.

Disclosures: Dr Gillinov serves as a consultant to AtriCure, Edwards Lifesciences, Medtronic, Abbott, CryoLife, Johnson \& Johnson, and ClearFlow. Dr Soltesz receives speaking and training honoraria from AtriCure, Abbott, Abiomed, and Edwards Lifesciences. Dr Weiss reported no conflicts of interest.

The Journal policy requires editors and reviewers to disclose conflicts of interest and to decline handling or reviewing manuscripts for which they may have a conflict of interest. The editors and reviewers of this article have no conflicts of interest.

Received for publication Aug 19, 2020; revisions received Aug 19, 2020; accepted for publication Aug 21, 2020; available ahead of print Sept 15, 2020.

Address for reprints: Marc Gillinov, MD, Department of Thoracic and Cardiovascular Surgery, Cleveland Clinic, Desk J4-1, 9500 Euclid Ave, Cleveland, OH 44195 (E-mail: gillinom@ccf.org).

JTCVS Techniques 2020;4:167-8

2666-2507

Copyright (C) 2020 The Authors. Published by Elsevier Inc. on behalf of The American Association for Thoracic Surgery. This is an open access article under the CC BY-NCND license (http://creativecommons.org/licenses/by-nc-nd/4.0/).

https://doi.org/10.1016/j.xjtc.2020.08.060

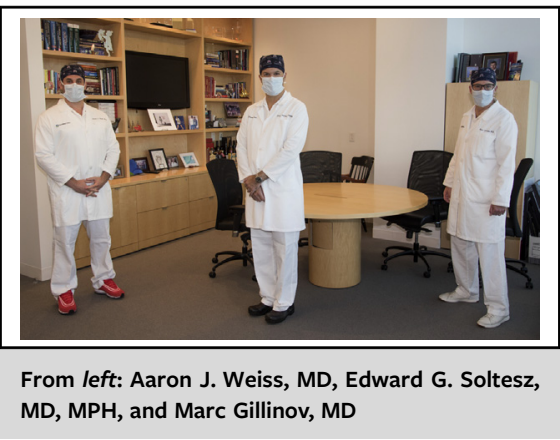

CENTRAL MESSAGE

A failed WATCHMAN device can

be managed by either excision or

exclusion, depending upon the

surgical scenario.

implantation, LAA thrombus, and patients with a preexisting atrial septal defect closure device present. Even after "successful" placement, peri-device flow has been noted in nearly one-third of patients. ${ }^{3}$ Minor leaks around the device do not constitute a surgical indication. However, large leaks and/or thrombus formation coupled with intolerance to anticoagulation (ie, bleeding) necessitate surgical consideration. With their insightful report of surgical strategies for failed WATCHMAN devices, Palmer and colleagues ${ }^{1}$ add to our knowledge and inform our management of complications that arise from intervening on the LAA.

Combining careful thought with surgical expertise, Palmer and colleagues ${ }^{1}$ offer a clear strategy for treatment of patients with a failed WATCHMAN device. They provide a case series of 5 patients, all of whom had both failed catheter ablation of AF and failed LAA occlusion with the WATCHMAN. The surgeons fixed both problems. In their manuscript, they detail for readers the when (when to address the failed WATCHMAN) and the how (how to safely manage the LAA in such instances).

Managing 5 patients with a surgical indication after a failed WATCHMAN implantation, the authors employed either exclusion or extraction, individualizing the therapy depending upon the unique characteristics present in each surgical situation. In patients with no previous surgery and who had a "neck" at the orifice of the LAA, thoracoscopic exclusion with a clip was preferred. However, in those patients requiring open surgery, device extraction followed by LAA exclusion was preferred. If extensive ingrowth precludes WATCHMAN extraction, the LAA 
orifice can be covered with a pericardial patch. As most of these patients will still have AF, the surgeon should also perform a biatrial maze procedure at the time of open surgery.

The advent of catheter-based procedures invariably creates new scenarios that mandate surgical innovation. Palmer and colleagues provide important guidance as this pattern repeats itself once again in the management of the LAA.

\section{References}

1. Palmer ST, Romano MA, Bolling SF, Fukuhara S. Surgical strategies for a failed Watchman device. J Thorac Cardiovasc Surg Tech. 2020;4:160-4.

2. Reddy VY, Doshi SK, Kar S, Gibson DN, Price MJ, Huber K, et al; PREVAIL and PROTECT AF Investigators. 5-Year outcomes after left atrial appendage closure: from the PREVAIL and PROTECT AF trials. J Am Coll Cardiol. 2017;70:2964-75.

3. Viles-Gonzalez JF, Kar S, Douglas P, Dukkipati S, Feldman T, Horton R, et al. The clinical impact of incomplete left atrial appendage closure with the Watchman device in patients with atrial fibrillation: a protect $\mathrm{AF}$ (percutaneous closure of the left atrial appendage versus warfarin therapy for prevention of stroke in patients with atrial fibrillation) substudy. J Am Coll Cardiol. 2012;59:923-9. 